\title{
RESPONSABILIDAD CONTABLE EN ITALIA DE LOS FUNCIONARIOS PÚBLICOS Y DE LOS ADMINISTRADORES EN LAS SOCIEDADES CONTRATISTAS MEDIANTE IN HOUSE PROVIDING: DISTINCIONES ENTRE LOS ACTIVOS DE LA EMPRESA Y LOS RECURSOS PÚBLICOS *
}

\author{
Gherardo CARULLO \\ Investigador de la Università degli Studi di Milano \\ Doctor en Diritto Amministrativo \\ por la Università degli Studi di Milano \\ LL.M. en el King's College de Londres \\ gherardo.carullo@unimi.it
}

1. La jurisprudencia de la Corte di Cassazione italiana (en adelante Corte o Cassazione) ha rechazado desde hace tiempo que el activo de una sociedad de capitales pueda (conforme a ley) encajar dentro de la definición de recursos públicos para garantizar el establecimiento y acción de la jurisdicción contable, aunque el capital social sea totalmente público. Esta decisión ha sido cogida por la Corte en sede de Derecho empresarial, en virtud de lo cual el activo de la sociedad se reputa diferente y autónomo respecto de aquel otro del socio ${ }^{1}$.

\footnotetext{
* Proyecto de investigación financiado por el Ministerio de Economía y Competitividad «Personas jurídicas y responsabilidad criminal: imputación (atribución, limitación, exclusión) y coautoría con personas físicas» (núm. referencia: DER2014-58217-R), coordinado por el profesor Joan J. Queralt de la Universidad de Barcelona. Última actualización: enero de 2016. Cabe señalar que, pendiente la publicación, se ha dictado el Decreto Legislativo de 19 de agosto de 2016, n. 175. El art. 12 del Decreto disciplinato indica expresamente la responsabilidad de las entidades participantes y de los miembros de los consejos de administración de las sociedades participadas. Cabe señalar también que, de acuerdo con lo que aquí se propuso, el decreto establece expresamente la responsabilidad de los administradores, o por lo menos de los titulares de la facultad de decidir por ellos.

1 Vid. la Sentencia de la Cassazione de 19 de diciembre 2009, núm. 26806, en la cual la Corte sostuvo que la completa independencia económica de una sociedad con respecto a los socios no permite responsabilizar a los socios públicos de los daños que la conducta ilegal de los órganos sociales puede haber causado a los activos de la institución: el patrimonio es y sigue siendo privado. La Corte ha aclarado así que por esta razón corresponde a los tribunales ordinarios encargarse de los daños sufridos por las empresas públicas como consecuencia de una conducta ilegal por parte de los directores o administradores de la empresa,
} 
Recientemente, la Cassazione ha introducido algunas excepciones relacionadas con ciertas específicas sociedades que participan en concursos públicos, como son los casos $\mathrm{RAI}^{2}, \mathrm{ENAV}^{3}$ y $\mathrm{ANAS}^{4}$, y, finalmente, con todas aquellas sociedades que presentan los requisitos para la contratación directa con la Administración pública a través del in house providing 5 .

En estos casos, según la opción elegida por la Cassazione, la relación entre el contratista y la Administración es tan estricta que se puede superar la dualidad de la personalidad jurídica — por lo menos, bajo un perfil patrimonial - para que se pueda restablecer una conexión con la jurisdic-

no siendo en este caso aplicable, teniendo en cuenta la personalidad jurídica autónoma de la sociedad, la jurisdicción del Tribunal de Cuentas. En ese sentido, ex multis, Sentencias de 15 de enero de 2010, núm. 519; de 23 de febrero de 2010, núm. 4309; de 5 de julio de 2011, núm. 14655; de 12 de octubre de 2011, núm. 20940; de 12 de octubre de 2011, núm. 20941; de 25 de marzo de 2013, núm. 7374; de 3 de mayo de 2013, núm. 10299, y de 2 de septiembre de 2013, núm. 20075.

${ }^{2}$ El principio afirmado por la Cassazione en las sentencias de la nota anterior ha sido sujeto a varias excepciones por la propia Corte. Sólo unos días después de la decisión antes mencionada de 19 de diciembre de 2009, núm. 26806, la Corte ha expedido otra decisión sobre el caso RAI (la televisión publica italiana, n.d.a.) en la que afirmó la jurisdicción contable dada la naturaleza sustancial de autoridad comparable a una Administración Pública de la RAI, no obstante el vestido formal de sociedad anónima (Sentencia de Cassazione de 22 de diciembre de 2009, núm. 27092). Sentencia que ha sido criticada por la doctrina italiana, por ejemplo, A. PACE, «La Corte di Cassazione ignora la storia, disapplica la legge e qualifica la Rai "ente pubblico"», Giur. cost., núm. 5 (2010), par. 5, y F. E. SANTONASTASO, «Ancora della Rai: "Così com'è oggi, è un centauro, con una natura in parte umana e in parte equina..."”, Giur. cost., núm. 5 (2010), quien igualmente señaló que la situación jurídica de un concesionario, donde no se aplica una legislación especial, sigue rigiéndose por el régimen ordinario.

3 En el caso ENAV (Sentencia de Cassazione de 3 de marzo de 2010, núm. 5032) la Corte, como sumariamente explica M. DI LuLLO, «Responsabilità degli amministratori di società a partecipazione pubblica e giurisdizione della Corte dei Conti: (soltanto) le società "in house" che gestiscono servizi pubblici sono pubbliche amministrazioni?», Foro amm., núm. 10 (2014), par. 3, aun sin llegar a (re)calificar expresamente a la persona jurídica de Derecho privado como un organismo público, ha valorado algunas características de la empresa, tales como: participación pública total; la realización de diversas actividades sobre la base de una disposición legal específica con los gastos a cargo del Estado; la predisposición de la empresa a un servicio público, o el sometimiento de la misma en la auditoría de la gestión financiera al Tribunal de Cuentas.

${ }^{4} \mathrm{La}$ Cassazione ha reafirmado recientemente estos principios, declarando expresamente que no se puede tratar a ANAS como una sociedad anónima de Derecho privado porque tiene las características esenciales de un organismo público, en relación a las cuales no es suficiente la adopción del modelo de organización que corresponde al de una empresa de Derecho privado (Sentencia de Cassazione de 9 de julio de 2014, núm. 15594). Pero esa decisión no ha sido aceptado sin críticas, entre otras muchas, por ejemplo, la de A. NiCODEMO, «La dubbia natura delle società pubbliche "figlie" della privatizzazione: il caso Anas», Foro amm., núm. 6 (2014), par. 4, según la cual todo esto no parece suficiente para dar a ANAS el carácter de institución pública, tratándola así como una Administración Pública en el sentido clásico.

5 Vid. Sentencias de Cassazione de 25 de noviembre de 2013, núm. 26283; de 2 de diciembre de 2013, núm. 26936; y de 24 de octubre de 2014, núms. 22609 y 22608. 
ción del Tribunal de Cuentas. En otras palabras, la Cassazione ha declarado que, subsistiendo todos los requisitos del in house, se puede superar la autonomía de la personalidad jurídica de la empresa, toda vez que el patrimonio de ésta puede ser considerado como público a los efectos de plantear la acción de la jurisdicción contable.

Esta solución, además de crear perplejidad — que compartimos- en la doctrina ${ }^{6}$, ha generado nuevos conflictos en el mismo Tribunal, que, para los propósitos del presente trabajo, ha calificado, por ejemplo, a aquellas sociedades in house como privatizadas ${ }^{7}$. Además, hay que añadir que también bajo el perfil de la seguridad jurídica y de la coherencia sistemática $^{8}$, la perspectiva adoptada por la Cassazione despierta, por lo menos, algunas perplejidades?

Por otra parte, el resultado alcanzado por la Corte suprema se ha juzgado insatisfactorio, incluso por el mismo Tribunal de Cuentas. Esta institución ha reputado erróneo determinar el reparto de jurisdicción según la (mera) subsistencia de los requisitos del in house, definiendo este criterio como fácilmente eludible y, por eso, incapaz de identificar el círculo de cobertura de la acción contable ${ }^{10}$.

Por tanto, parece justo preguntarse si, al fin de garantizar la represión de conductas perjudiciales para el activo público, no hay alguna ruta más apropiada. Sobre todo porque parecen no faltar las herramientas que garantizan que no se dejen sin castigar conductas que sean perjudiciales para los bienes públicos, penalizando a los responsables del daño sin nece-

${ }^{6}$ Entre los muchos estudios sobre este tema se pueden recordar M. AnTONIOLI, Società a partecipazione pubblica e giurisdizione contabile, Milano, Giuffrè, 2008, p. 148, o S. VALAGUZZA, «Le società a partecipazione pubblica e la vana ricerca della coerenza nell'argomentazione giuridica», Dir. amm., núm. 3 (2014), par. 4.

7 La misma Cassazione, Sección Trabajo, ha declarado recientemente en repetidas ocasiones que el hecho de tener en gestión un servicio público local no modifica la situación jurídica de la empresa privada con respecto a los efectos de la seguridad social de las relaciones laborales (Sentencia de Cassazione, Sección Trabajo, de 20 de junio 2014, núm. 14098, y jurisprudencia citada por la misma Corte).

8 Esto ha sido confirmado por la reciente Sentencia de la Corte dei Conti, Prima Sezione Centrale di Appello, de 20 de febrero de 2015, núm. 178, que no estaba de acuerdo expresamente con lo que se decidió por la Cassazione sobre el reparto de jurisdicción.

9 Vid. R. UnsI, «Il cammino disorientato delle c.d. società in house», Dir. Ec., núm. 3 (2014), p. 557, y G. SALCUNI, «I "circuiti” ed i "cortocircuiti” nelle scelte dei modelli di tutela fra pubblico e privato le qualifiche pubblicistiche e le posizioni di garanzia», Riv. it. dir. e proc. pen., núm. 2 (2014).

${ }_{10}$ En este sentido, vid. la Sentencia de la Corte dei Conti, Prima Sezione Centrale di Appello de 20 de febrero 2015, núm. 178, que señala el peligro de dejar el reparto de jurisdicción a una elección esencialmente basada en la disponibilidad de la Administración misma. 
sidad de recalificar como públicas, a efectos de la contabilidad, a esas entidades que han sido deliberada y expresamente creadas como privadas. Esto se puede lograr evitando que, al mismo tiempo y por medio de estructuras corporativas más o menos complejas, se diluyan las responsabilidades contables de los que son los dueños reales de las funciones públicas ${ }^{11}$. Además, esto permite evitar que, a través de una compleja cadena de relaciones corporativas, se haga más complicado identificar la causa del daño con el fin de ocultar las propias responsabilidades.

Antes de trasladarnos a este análisis, todavía parece conveniente aclarar algunos problemas que se encuentran a la hora de definir y explicar el controvertido concepto de sociedad pública y otras ideas relacionadas, cuyo uso podría ser un presagio de fáciles malentendidos, como demuestra la misma incerteza de la jurisprudencia sobre este punto ${ }^{12}$.

2. Hay que recordar que la excepción que permite derogar la obligación de licitación y de tener una contratación directa a través del in house providing es, sin duda, de derivación europea. No sucede así con la figura de la sociedad in house. A nivel europeo, de hecho, el in house representa únicamente una —excepcional $-{ }^{13}$ modalidad de contratación (internalizada), y, en este sentido, describe las características que una entidad contratista debe poseer. Hay que tener en cuenta que la herramienta empresarial, en la perspectiva europea, no se identifica como un instrumento necesario o favorecido de internalización por in house. Esto acontece porque, de los dos, la herramienta empresarial es una de las menos adecuadas a la luz de los requisitos europeos ${ }^{14}$.

${ }^{11}$ En consonancia con esta idea vid., en época anterior a estas sentencias, D. SORACE, «La responsabilità amministrativa di fronte all'evoluzione della pubblica amministrazione: compatibilità, adattabilità o esaurimento del ruolo?», Dir. amm., núm. 2 (2006), par. 4.1.

${ }_{12}$ Como bien explica sumariamente C. IвBA, «Responsabilità degli amministratori di società pubbliche e giurisdizione della Corte dei Conti», Giur. comm., núm. 5 (2012), par. 5, la condición de organismo público no tiene nada que ver con la cuestión de la jurisdicción, ya que sólo afecta a la aplicación de las normas de contratación pública y no a otros campos.

${ }^{13}$ En este punto hay que destacar que el concepto de excepcionalidad se entiende aquí en el sentido aceptado por el Tribunal de Justicia, que describe el house providing como excepción solamente en relación a las condiciones de aplicación de las directivas europeas en materia de procedimientos públicos y, por tanto, en relación a la interpretación de sus requisitos.

${ }_{14}$ Sobre la forma jurídica de la entidad in house, desde hace mucho tiempo G. GRECO, «Gli appalti pubblici di servizi», Riv. it. dir. pubbl. com., núm. 6 (1995), p. 1286, advirtió que la creación de una sociedad anónima es algo particularmente adecuado para integrar los requisitos del in house. Más recientemente vid. G. GRÜNER, «Compiti e ruolo del socio pubblico: direzione (società miste) e dominio (società in house)», Dir. Ec., núm. 2 (2012), p. 9, y G. BASSI, «Le determinanti del controllo analogo in forma collettiva nell'istituto dell' in house providing», Riv. Trim. App. núm. 2 (2009), pars. 3 y 5 . No obstante, hay que tener en 
Otro elemento a tener en cuenta es que, en la perspectiva europea mencionada, el primer elemento necesario para que se pueda hablar de contratación a través del in house providing — como excepción a la obligación de licitación - es que el contrato se refiera a una actividad económica en el sentido reconocido a nivel europeo ${ }^{15}$. Si esto no se cumple, no existe ningún deber (europeo) de licitación, y, por lo tanto, tampoco las excepciones relativas, como aquella del in house providing, se aplican.

Esa condición es de particular importancia para nuestros propósitos, ya que el desarrollo de las actividades empresariales es condición previa para la aplicación concreta de las normas de derivación europea en materia de procedimientos públicos ${ }^{16}$.

Una vez aclarado que, en el amplio sentido europeo, la actividad es económica ${ }^{17}$, se debe tener en cuenta que las normas europeas sobre la libre circulación desempeñan un papel importante, a excepción de las especialidades admitidas por el mismo ordenamiento europeo. Estas disposiciones especiales todavía tienen una interpretación muy estricta. Por ejemplo, las condiciones del in house — que tienen su origen en las normas relativas a las libertades fundamentales - no permiten ninguna derogación de las disposiciones enumeradas en los arts. 101 y ss. TFUE, que hablan de competencia. En este contexto, por supuesto, las categorías nacionales no tienen ninguna relevancia.

Por este motivo, este análisis se centrará en aquellos casos en que la sociedad pública con los requisitos para la contratación in house lleva a cabo actividades económicas según la amplia noción europea.

Aceptando este enfoque, podemos dejar de lado por el propósito de este estudio el viejo debate -italiano- sobre la naturaleza y las normas que regulan las sociedades públicas ${ }^{18}$, las cuales se pueden clasificar

cuenta que, como explica D. U. GALETTA, «Forme di gestione dei servizi pubblici locali ed in bouse providing nella recente giurisprudenza comunitaria e nazionale», Riv. it. dir. pubbl. com., núm. 1 (2007), pars. 3.4, en la Sentencia de 6 de abril de 2006 en el asunto C 410/04, $A N A V$, el Tribunal de Justicia dijo que, en perspectiva europea, no hay ninguna incompatibilidad de principio entre el in house y la forma societaria.

15 Sobre este concepto vid., por todos, A. Jones y B. Sufrin, EU Competition Law, 5. a ed., Oxford, Oxford University Press, 2014, p. 129, quienes resumen el problema afirmando que la cuestión central en la determinación de si una entidad se dedica a actividades económicas o a tareas de carácter público parece depender de si la oferta de bienes o servicios en el mercado podría ser llevada a cabo por una empresa privada para obtener una utilidad determinada.

${ }^{16}$ Estas disposiciones, de hecho, constituyen la base jurídica de las normas de los Tratados relativas a las libertades fundamentales. Vid. D. U. GALETTA y G. CARULlO, «Gestione dei servizi pubblici locali e in house providing: novità, auspici e scenari futuri in una prospettiva di de-frammentazione del sistema», Riv. it. dir. pubbl. com., núm. 1 (2016), par. 2.

17 Según lo explicado por los autores citados en la nota 15.

18 Problema que aún no está resuelto. Vid. G. Oppo, «Pubblico e privato nelle socie- 
según la definición europea de «operador económico», independientemente del hecho de que se hable de «sociedades públicas», «organizaciones de derecho público», «empresas públicas» u otras categorías asimismo públicas ${ }^{19}$.

Entre las categorías nacionales, no hay ninguna concordancia entre la noción de sociedad y el tema tratado. Si las actividades tienen un carácter económico, el hecho de que, bajo el perfil nacional, sean clasificadas como «actividades administrativas privatizadas» ${ }^{20}$, no tiene mucha importancia. Bajo un perfil continental, no cabe duda de que, si se proporcionan bienes o servicios, se puede siempre aplicar la disciplina competitiva europea.

3. Actualmente, en el Derecho nacional italiano, no hay ni una norma, de carácter ordinario o especial que haya establecido de una vez por todas y de forma exclusiva la existencia de la jurisdicción contable relacionada con las conductas de los administradores de las sociedades contratistas in house. En el pasado, por el contrario, había y todavía hay muchas normas que contribuyen a sembrar dudas sobre la mejor solución a escoger.

Entre estas segundas, por ejemplo, podemos nombrar aquellas normativas que habían hecho que las sociedades contratistas in bouse se sometieran al pacto de estabilidad interno ${ }^{21}$, es decir, normas que aún requieren

tà partecipate», en Atti del Convegno «Le società pubbliche», Venezia, Veneta, 2004, p. 6, y F. Galgano, Il nuovo diritto societario, Padova, CEDAM, 2003, p. 439.

19 Por el contrario, no son convincentes las posiciones según las cuales las actividades in house no serían de carácter empresarial, como afirma G. TERRACCIANO, «La natura giuridica delle società a partecipazione pubblica e dei consorzi per la gestione dei servizi pubblici locali», Foro amm. TAR, núm. 7-8 (2010), par. 5. Sin embargo, esta perspectiva nunca ha sido aceptado por el Tribunal de Justicia y además está en contradicción con las condiciones de aplicación de las normas sobre los procedimientos de licitación pública —es decir, la naturaleza económica de las actividades realizadas - Cabe, por tanto, clarificar la noción de mercado: una cosa es la distinción entre la autoproducción y el mercado, según la cual la actividad interiorizada se puede decir que sea retirada del mercado de los contractos públicos, y el otro es el mercado interior de la Unión Europea, tal como se define en los Tratados. Con respecto a este último, es indiferente la naturaleza pública o privada del sujeto; sólo es relevante si las actividades ejercitadas poseen carácter económico.

${ }^{20}$ Expresión utilizada originalmente por la Corte Costituzionale en su Sentencia de 13 de agosto de 2008, núm. 326, sobre la norma del art. 13 del Decreto-ley 223/2006 y luego utilizada también por la jurisprudencia administrativa italiana. Vid. Sentencias del Consiglio di Stato de 4 de agosto de 2011, núm. 17; de 11 de enero de 2011, núm. 77, y de 5 de marzo de 2010, núm. 1282.

${ }^{21}$ Art. 3 bis, apartado 5, del Decreto-ley núm. 138/2011. Sin embargo, fue derogado por el art. 1, párrafo 559, letra a), de la Ley núm. 147/2013. El párrafo 557 del mismo art. 1, que modificó el art. 18, apartado 2 bis, del Decreto-ley núm. 112/2008, ha establecido que las empresas públicas o aquellas sujetas al control público deben reducir los gastos de personal. 
la aprobación de un balance consolidado que incluya las cuotas de algunas organizaciones públicas, o sea, las disposiciones que, en algunos casos, obligan a las Administraciones a dejar de lado cantidades iguales a las pérdidas de la filial en proporción a la participación ${ }^{22}$.

Ninguna de estas disposiciones es definitiva, como demuestra el debate doctrinal surgido después de la solución aceptada por la Cassazione sobre la titularidad individual del activo de la entidad in house ${ }^{23}$. Dependiendo del punto de vista elegido, estas normas pueden ser leídas como confirmación de la jurisdicción contable o como reconocimiento de la diferente y autónoma situación del activo de las filiales. Otro grupo de disposiciones invocadas en apoyo a la ampliación de la jurisdicción contable a las sociedades controladas y, en particular, a las in house, es el art. 4 del Decretoley de 6 de julio de 2012, núm. 95; específicamente, el párrafo 12 establece que, en caso de violación de algunas de las obligaciones que sirven para limitar los gastos de las empresas controladas, los administradores ejecutivos y los dirigentes responsables de la empresa responden, en concepto de daño a los ingresos del Estado, por salarios y compensaciones pagadas en virtud de los referidos contratos.

Sin embargo, la referencia a dichas normas no conduce a una solución concluyente. Éstas deben ser leídas con un carácter derogatorio, según el mismo art. 4, párrafo 13, del citado Decreto ${ }^{24}$, cuya redacción ha excluido cualquier desviación del modelo financiero, no explícitamente establecida por el legislador ${ }^{25}$.

Otras normas que se encuentran en esta línea tampoco parecen ayudar mucho. Como explica Ibba, tales normas son más o menos declaradamente útiles para resolver problemas específicos y concretos de respon-

22 Vid. art. 1, párrs. 550 y ss., de la Ley núm. 147/2013.

${ }^{23}$ Como ya se ha señalado, hay una separación de bienes, no de titularidad de los activos, entre la Administración y la empresa (ex multis Sentencia de Cassazione de 10 de marzo de 2014, núm. 5491).

${ }^{24}$ La norma establece que: «Le disposizioni del presente articolo e le altre disposizioni, anche di carattere speciale, in materia di società a totale o parziale partecipazione pubblica si interpretano nel senso che, per quanto non diversamente stabilito e salvo deroghe espresse, si applica comunque la disciplina del codice civile in materia di società di capitali» [«las disposiciones del presente artículo y las demás disposiciones, incluidas las de carácter especial, con respecto a las empresas en participación pública total o parcial, se interpretan en el sentido de que (...) se aplica la disciplina del Código Civil en relación con las sociedades anónimas»].

${ }^{25}$ Vid. en este sentido la doctrina citada en la nota 6 y también R. URSI, «Il cammino disorientato...», op. cit., p. 560, y M. MAZzAMUTO, «Fallibilità o meno delle società in house tra diritto privato e diritto pubblico, garanzia statale dei debiti degli enti pubblici (CEDU) e divieto di aiuti statali (UE)», Dir. Ec., núm. 3 (2014), p. 551. 
sabilidad que, justamente, la jurisprudencia no valora en su justa medida para tratar de obtener principios generales a contrario ${ }^{26}$.

4. Teniendo en cuenta la importancia que la Cassazione ha dado a la existencia, cuando menos, de los requisitos para la contratación in house a la hora de identificar la jurisdicción contable, puede ser útil señalar las características principales para delinear el régimen de responsabilidad de los funcionarios públicos y de los administradores de las sociedades contratistas in house.

Desde esta perspectiva, es importante recordar que el requisito de control análogo requiere que las más importantes decisiones de gestión de la organización sean aprobadas por la organización controlante ${ }^{27}$.

Así, a partir de este dato, se podría decir que para aquellas decisiones importantes que no pertenecen a los órganos de gobierno, éstos no pueden ser declarados responsables en relación con las determinaciones heteroimpuestas, las que vienen de fuera.

En esta perspectiva, se puede recordar el art. 179 de la Ley española 33/2003, de 3 de noviembre, sobre el patrimonio de las Administraciones Públicas. Según esta norma, de hecho, los administradores de las sociedades con capital del Estado están expresamente exentos de responsabilidades hacia la sociedad, sus accionistas y acreedores sociales en caso de daños debidos a decisiones de gestión tomadas para respetar las instrucciones dictadas por el Ministerio competente de referencia ${ }^{28}$.

Todo esto funciona bien, excepto que, como ya se ha explicado, el marco regulatorio italiano respecto a la responsabilidad de los administradores de sociedades públicas no está tan claro ${ }^{29}$. Así, más allá del limitado

${ }^{26}$ Así, en C. IBBA, «Responsabilità degli amministratori...», op. cit., par. 4, en relación al art. 16 bis de la Ley de 28 de febrero de 2008, núm. 31, y al art. 3 del Decreto-ley de 28 de agosto de 2008, núm. 134.

${ }_{27}$ Para un análisis del contenido del requisito del control análogo, especialmente a la luz de las nuevas directivas sobre los contratos públicos, vid. G. CARULlO, «Riflessioni su alcune aperture del legislatore europeo in tema di in house, anche in prospettiva dei corrispondenti limiti nazionali per le società strumentali», Riv. it. dir. pubbl. com., núm. 5 (2014).

28 «Los administradores de las sociedades a las que se hayan impartido instrucciones en los términos previstos en el artículo anterior actuarán diligentemente para su ejecución y quedarán exonerados de la responsabilidad prevista en el art. 133 del Real Decreto Legislativo 1564/1989, de 22 de diciembre, por el que se aprueba el texto refundido de la Ley de Sociedades Anónimas, si del cumplimiento de dichas instrucciones se derivaren consecuencias lesivas».

${ }^{29}$ No es casualidad que la doctrina italiana haya llegado a adoptar un Manifiesto por la Reforma de las Empresas Públicas. Vid. L. R. Perfetti, A. Maltoni, F. Goisis y M. AntonioLI, «Manifesto per una riforma di sistema delle società a partecipazione pubblica», Dirittodeiservizipubblici.it, 2015, par. 16. 
alcance de la norma española y con el fin de obtener un resultado similar, en nuestra legislación se necesita alguna reflexión más compleja sobre las relaciones financieras que pueden existir entre la Administración principal y la Administración filial.

En este sentido, se debe tomar en consideración que la noción de control análogo, según la definición de la Corte de Justicia y de otras instituciones similares, después de la intervención del legislador europeo y del Derecho positivo de la Unión, no impone ninguna disciplina para con la responsabilidad.

Tampoco las normas europeas que tratan de procedimientos públicos y las excepciones relacionadas con aquéllas dan indicación alguna sobre el régimen de responsabilidad de los administradores. Es una opción puramente nacional que, de alguna manera —más que nada por el principio de neutralidad determinado por el art. 345 TFUE- ${ }^{30}$, se puede considerar como una imposición europea necesaria. De hecho, de los dos, el Derecho europeo ofrece algunos instrumentos que sirven para garantizar que, con el fin de controlar las ayudas estatales, el activo de la organización pública sea bien distinto (y distinguible) de aquel otro de la empresa que trabaja en el mercado interno (también en régimen de autoproducción) ${ }^{31}$.

El contexto europeo aún puede ser útil bajo una perspectiva diferente si se consideran las consecuencias de la aplicación de las reglas de competencia de los arts. $101 \mathrm{y}$ ss. TFUE, y, en particular, aquella del apoyo del Estado. En el contexto de la «Economía Social de Mercado», ex art. 3, párrafo 3, TFUE ${ }^{32}$, se puede pensar que también en el sector de los servi-

30 Sobre el art. 345 TFUE y el principio de neutralidad vid. D. U. GALETTA, «Forme di gestione...», op. cit., par. 3.1; C. FRATEA, «Articolo 345 TFUE», en F. POCAR y M.C. BARUFFI (eds.), Commentario breve ai trattati dell'unione europea, Trento, CEDAM, 2014, p. 1540; A. MaLtoni, «Gli atti "prodromici” delle PA che incidono sulla struttura e sul funzionamento delle società partecipate: una categoria da definire. Considerazioni in tema di limiti dell'autonomia negoziale delle PA», Riv. it. dir. pubbl. com., núm. 1 (2013), par. 6.1; G. Rossi, L'impresa europea di interesse generale, Milano, Giuffrè, 2006, p. 3; L. SALTARI, Amministrazioni nazionali in funzione comunitaria, Milano, Giuffrè, 2007, p. 75, y R. CARANTA, I contratti pubblici, Torino, Giappichelli, 2012, p. 25.

${ }^{31}$ Este es uno de los principales objetivos de la Directiva 2006/111/CE, de 16 de noviembre de 2006, relativa a la transparencia de las relaciones financieras entre los Estados miembros y las empresas públicas, así como a la transparencia financiera de determinadas empresas, cuyo objetivo es, entre otros, precisamente «permitir que se diferencie claramente el papel del Estado como poder público y como propietario» (octavo considerando).

32 Según el cual, la Unión Europea «obrará en pro del desarrollo sostenible de Europa basado en un crecimiento económico equilibrado y en la estabilidad de los precios en una economía social de mercado altamente competitiva». En cuanto a la definición de «economía social de mercado», basta recordar aquí lo que explica M. LiBERTinI, «A "highly com- 
cios públicos está presente el impulso de la Unión Europea hacia la superación definitiva de las ayudas al funcionamiento, es decir, a aquellas ayudas desembolsadas de modo sustancial para hacer frente a las actividades económicas no autosuficientes ${ }^{33}$.

En este sentido, la Comisión, en el último paquete de modernización a ella debido ${ }^{34}$, ha dejado claro que, en la evaluación de la compatibilidad ex art. 108 TFUE de su competencia, dará prioridad a medidas instrumentales para el desarrollo y la eficiencia del mercado de los servicios públicos. Así que, a excepción de lo que es necesario para neutralizar los mayores costes derivados de las obligaciones de servicio público, el mero soporte financiero de gestiones en pérdida es ciertamente incompatible con el mercado europeo.

Lo que es muy importante, partiendo de la base de que este principio se aplica también cuando la Administración considera erróneamente que, a través de una gestión pública por medio de una autoproducción, serán mejor tutelados los interés públicos, aunque esta gestión sea en pérdida y necesite por eso refinanciaciones públicas.

Por lo tanto, se puede considerar como pacífica la circunstancia que prevé que las gestiones públicas no pueden beneficiarse de ayuda al mero funcionamiento, debiendo ser económicamente sostenibles sin ninguna medida de apoyo —en el sentido del art. 107, párrafo 1, TFUE, es decir, al neto de posibles compensaciones por obligación de servicios públicos- ${ }^{35}$. Esto lleva a la consecuencia de que una gestión no económicamente sostenible llevará a la disminución gradual de los activos hasta que se agoten.

petitive social market economy" as a founding element of the European economic constitution», Conc. Merc., núm. 1 (2011), pp. 491 y ss.: «Esta teoría económica se basa en la idea de que entre las empresas y el Estado — entendido como poder autoritario- deben ser las primeras las que prevalezcan, sin perjuicio de la intervención de la autoridad de manera complementaria allí donde el mercado no sea capaz de garantizar la plena realización de los objetivos públicos perseguidos».

33 Acerca de las cuales nos remitimos a las consideraciones expuestas en G. CARULLO, «Aiuti di stato: La "modernizzazione" del ruolo dello "Stato finanziatore" quale motore dello sviluppo dei Servizi di interesse económico generale», Conc. Merc., núm. 1 (2015).

34 Vid. la Comunicación de la Comisión sobre la modernización de las ayudas estatales de la UE del 8 de mayo de 2012 [COM (2012) 209 final], y los actos sectoriales.

${ }_{35}$ Hay, por supuesto, que tener en cuenta que, de acuerdo con la famosa sentencia Altmark (asunto C-280/00), una medida no constituye una ayuda en el sentido del art. 107, párr. 1, TFUE, donde -integrando los cuatro requisitos establecidos por la Corte-, en resumen, aquélla está destinada sólo para hacer frente a los mayores costes en que incurre el operador económico con el fin de cumplir su misión de servicio público confiada a él por la autoridad pública. 
Si es así, aun con el fin de individualizar las responsabilidades que hayan llevado a esta situación, parece oportuno verificar cuál sea la posición determinada por la Administración y escoger el modelo de gestión en el momento genérico de esa relación. De tal manera se puede aclarar si la consiguiente antieconomicidad del servicio y, en consecuencia, la reducción de los activos ha sido o no determinada por decisiones de gestión inadecuadas, o si la gestión en pérdida ha sido la inevitable derivación de un modelo de organización destinado al fracaso. Lo mismo valdrá por cada sucesiva intervención de la Administración que modifique la estructura existente, aunque sea sólo por aportación de capital.

5. En los últimos años, el legislador italiano ha introducido, para la mayoría de las Administraciones, la obligación de redactar una relación motivada que explique las razones por la cuales se ha elegido un determinado modelo de gestión de un servicio público y la compatibilidad de este modelo con el Derecho europeo ${ }^{36}$. Sin embargo, el contenido innovador de la norma se ha visto reducido por el hecho de que, desde hacía tiempo, jurisprudencia $^{37}$ y doctrina ${ }^{38}$ ya habían afirmado esta obligación de las Administraciones.

Esta carga o deber constituye un antecedente necesario de la contratación que podrá ser dispuesta sólo después de una instrucción adecuadamente motivada. Y esto no es algo sin consecuencias cuando se examinan los reflejos que tal evaluación pueda tener en la gestión de la sociedad.

Las modalidades de prestación del servicio y las relativas elecciones de gestión no podrán prescindir del encuadramiento inicial hecho por la Administración. Los confines entre los cuales se debe mover la gestión internalizada son definidos por la propia Administración de acuerdo con los límites establecidos en el contexto europeo con esta secuencia de actos, los cuales terminan con la contratación.

36 Vid. el art. 34, apartado 20, del Decreto-ley de 18 de octubre de 2012, núm. 179.

37 Vid. las Sentencias del Consiglio di Stato de 12 de marzo de 1990, núm. 374; de 18 de abril de 2007, núm. 456, y de 11 de febrero de 2013, núm. 762. En Europa vid. la Sentencia del Tribunal de Justicia de 13 de octubre de 2005, asunto C-458/03, Parking Brixen, párr. 63, o también la Sentencia de 6 de abril de 2006, asunto C-410/04, $A N A V$, párr. 26.

${ }^{38}$ Ex multis, A. MASSERA, «Il partenariato pubblico-privato e il diritto europeo degli appalti», Riv. it. dir. pubbl. com., núm. 5 (2005), par. 5; en relación con el art. 23 bis, M. Dugato, «La manovra finanziaria prevista dalla legge núm. 133/2008», Giornale Dir. Amm., núm. 12 (2008); R. CAVAllo PerIN, «I principi come disciplina giuridica del pubblico servizio tra ordinamento interno ed ordinamento europeo», Dir. amm., núm. 1 (2000); C. VOLPE, «L'affidamento in house di servizi pubblici locali e strumentali: origine ed evoluzione più recente dell'istituto alla luce della normativa e della giurisprudenza europea e nazionale», Giustamm.it, núm. 3 (2014), par. 6, y M. G. Roversi MONACO, «I caratteri delle gestioni in house», Giornale Dir. Amm., núm. 12 (2006), par. 3. 
En esta perspectiva, hay que recordar que uno de los requisitos fundamentales para la contratación in house es el respeto al elemento de prevalencia de las actividades. Se requiere que, por lo menos, el 80 por 100 de la facturación de la sociedad tenga que ser realizado en el desarrollo de las funciones asignadas por la organización principal.

Por eso, si el territorio de competencia de la Administración contratista es pequeño y ésta ha subcontratado el servicio a una sociedad por ella controlada, será muy importante que la resolución para la selección del modelo de gestión in house aclare si una organización de este tipo es efectivamente sostenible, teniendo en cuenta el numero limitado de usuarios ${ }^{39}$.

En una situación de este tipo, no se podrán obviamente justificar las pérdidas sufridas con la excusa de mayores gastos debidos a obligaciones de servicio público, ya que el resultado debe ser evaluado conforme al valor neto de dichos gastos y de las relativas compensaciones ${ }^{40}$. Dichas sumas deberían ser ya consideradas en la resolución de contratación y, por eso, el resultado no debería verse influenciado de ninguna manera, ni por una forma, ni por otra, si hablamos de gastos e ingresos ${ }^{41}$.

Por lo tanto, en el caso de que la Administración no haya realizado un análisis de factibilidad económica adecuado, que demuestre la economía y la sostenibilidad del modelo de gestión, se puede concluir que habrá consecuencias en el régimen de responsabilidades contables por las pérdidas de gestión sufridas. En esta situación, las pérdidas de la organización serán una consecuencia directa e inevitable de la elección de la Administración de un modelo antieconómico.

39 Lo cual, en el panorama italiano, no es una hipótesis meramente teórica, como lo demuestra el hecho de que, en las líneas del servicio de transporte público local, A. BorTANi y C. CAMBINI, «Le gare per i servizi di trasporto locale in Europa e in Italia: molto rumore per nulla?», Ec. e pol. ind., núm. 122 (2004), par. 3, han explicado que, desde un punto de vista organizativo, las rutas se trazan, esencialmente, siguiendo los límites jurisdiccionales del sujeto provincial, sin asegurarse de que se llevaran a cabo estudios a nivel regional sobre la existencia de economías de escala que podrían conducir a la agregación de las cuencas vecinas.

${ }^{40}$ Es importante precisar que cuando se habla de gestión en pérdida se entiende referida al neto de los mayores gastos por obligaciones derivadas del servicio público y de las relativas compensaciones suministradas por la Administración, que no deben comportar ninguna ventaja según el art. 107, párr. 1, TFUE.

${ }^{41}$ Por el contrario, si la compensación no es suficiente para cobrar los mayores gastos del servicio publico, sería ciertamente posible revisar el plan de compensación a condición de que esto no suponga una modificación sustancial de la financiación. Por el contrario, si la compensación es excesiva sería necesario proporcionar un plan de recuperación con el fin de evitar convertir el excedente en una ayuda estatal. De todos modos, no parece que estos casos puedan tener un impacto significativo en la delimitación del régimen de la responsabilidad. 
Por el contrario, no será posible decir que esto ha sido determinado por los administradores de la sociedad. En otras palabras, no se podrá decir que ellos son los responsables por la disminución de los activos del capital social si ésta es la mera consecuencia del modelo de contratación -ineficiente- escogido por la Administración principal.

$\mathrm{Ni}$ tampoco podría influir sobre esta conclusión la objeción de que, en la determinación de las pérdidas derivadas de la gestión, hayan influido elecciones equivocadas de los administradores. $\mathrm{Y}$ esto por dos razones.

Primera: hay que considerar que, tratándose de una sociedad contratista in house, el requisito del control análogo impone que las elecciones referidas a cuestiones de gestión fundamentales no son responsabilidad de la Administración de la sociedad, sino de la organización accionista.

Esto, sin embargo, es una garantía que tutela al socio público accionista. Una vez que la actividad económica haya empezado según las prescripciones de la Administración, de hecho, los administradores de la sociedad no pueden tomar ninguna decisión importante que modifique la estructura determinada por la Administración.

Esto no es todo. Hay que añadir que si el servicio no es de ninguna manera económicamente sostenible, el daño se produce cuando la Administración adopta el modelo de gestión. La producción de los daños puede ser así identificada plenamente en la decisión y en la posterior ejecución de la decisión de la Administración a través de la cual ha sido transferido a la empresa el capital público.

En otras palabras, cuando la resolución sobre el modelo de gestión a elegir no prueba la viabilidad económica de la operación —en función, repetimos, del neto de las compensaciones públicas legítimas-, la Administración misma es inmediatamente responsable de los daños, ya que desde el mismo momento en que se toma la decisión, ésta comienza a generar pérdidas.

Esta conclusión se ve corroborada por el fin sancionador que la Cassazione misma ha identificado repetidamente para la disciplina de la responsabilidad contable ${ }^{42}$. Si el objetivo es castigar a aquellos que han causado el daño, se debe concluir que aquellos que son exclusivamente responsables de la producción del daño deben ser sancionados (los funcionarios públicos), y no los que están privados de cualquier poder de decisión sobre el

${ }^{42}$ De hecho, la Cassazione ha dejado claro que la acción contable es completamente diferente de las acciones de responsabilidad social y contra los acreedores de la sociedad cubiertas por el Código Civil. Vid. Sentencia de Cassazione de 19 de diciembre de 2009, núm. 26806. 
punto central (los administradores de la sociedad). Lo cual, sin embargo, no excluye que se pueda hablar de negligencia concurrente de los directores de la empresa.

Bajo este enfoque, se puede añadir que para muchos servicios públicos - como, por ejemplo, el transporte público local— la evaluación de la sostenibilidad económica es bastante fácil. No sólo los usuarios potenciales pueden ser sencillamente cuantificados sobre la base de los datos históricos y estadísticos, sino también los costes mismos del servicio a través de un análisis de las cuentas de otras Administraciones similares.

Se puede tener confirmación de esto a partir de un razonamiento $a$ contrario, si consideramos la cuestión desde la perspectiva opuesta. En un contexto en el que los costes son determinables y las tasas son comparadas con ellos, con la cobertura de las obligaciones del servicio público, parece bastante improbable que una empresa media eficiente no pueda funcionar y tenga pérdidas en la gestión, allí donde la Administración ha dado pasos para seleccionar un modelo eficiente y económicamente sostenible.

Así, la relación del citado art. 34, párrafo 20 —en que se requiere un análisis económico realista y correctamente estructurado-, si es correctamente aplicada ${ }^{43}$, puede resolver el problema de la determinación de la jurisdicción contable. Cuando la elección del modelo de gestión es económicamente insostenible, la responsabilidad debe ser de los funcionarios de la Administración.

6. Las normas europeas sobre ayudas de los Estados garantizan que todos los agentes económicos, públicos o privados, no puedan recibir fondos estatales de cualquier tipo. La aplicación de esta normativa ha dado lugar a la aparición de varias herramientas para distinguir los recursos que deben ser considerados como públicos y los que, por el contrario, pueden ser considerados como recursos propios de cualquier operador económico.

En primer lugar, se pueden recordar las normas de la Directiva sobre la Transparencia ${ }^{44}$, los mecanismos para el cálculo de las compensaciones por obligaciones derivadas de servicio público ${ }^{45}$, y el principio del inver-

${ }^{43}$ Lo que no es siempre cierto, como demuestran varios casos en los cuales la jurisprudencia criticó la decisión tomada por la Administración por no haber dado razones suficientes acerca de la conveniencia del modelo de gestión elegido. Vid., por ejemplo, TAR Lazio, Latina, Sec. I, de 21 noviembre de 2012, núm. 862; TAR Lazio, Sec. III Quater, de 4 de enero de 2012, núm. 58, y TAR Nápoles, Sec. IV, de 8 de septiembre de 2014, núm. 4797.

${ }_{44}$ Directiva 2006/111/CE, de 16 de noviembre de 2006.

45 Vid. G. Carullo, «Aiuti di stato: La "modernizzazione" del ruolo dello "Stato finanziatore"», op. cit. 
sor privado en la evaluación de la compatibilidad de las medidas estatales, en el sentido del art. 107, párrafo 1, TFUE ${ }^{46}$.

El uso de estas herramientas europeas permite enmarcar, en una perspectiva puramente nacional, la naturaleza de las compensaciones a partir de obligaciones de servicio público recibidas por una sociedad controlada por una Administración, a fin de comprobar si éstas están realmente conectadas o no con un interés público inmediato, identificado y determinado específicamente.

Bajo la primera condición establecida por la sentencia del famoso caso Altmark, «la empresa beneficiaria debe estar efectivamente encargada de la ejecución de obligaciones de servicio público y éstas deben estar claramente definidas» ${ }^{47}$. Además las condiciones de compatibilidad de las ayudas son vinculantes y la modificación de una medida ya declarada compatible implica una nueva notificación, de conformidad con el art. 108, párrafo 3, TFUE ${ }^{48}$.

Por tanto, las compensaciones por obligaciones derivadas de servicio público, como ayuda estatal declarada compatible, están estrechamente funcionalizadas y orientadas a perseguir un interés público preciso y predeterminado. En consecuencia, estos recursos están a disposición de la sociedad para alcanzar un objetivo (u objetivos) de interés público, identificado por la Administración cuando ésta aprobó el desembolso de los fondos.

En consecuencia, el vínculo funcional entre dichos recursos y los intereses públicos específicos identificados por la Administración puede dejar un elemento crucial para evaluar la responsabilidad de aquellos que hayan utilizado esos recursos para fines distintos de los predeterminados por la Administración.

De esta manera se puede, de hecho, conectar la jurisdicción contable a la naturaleza y a la funcionalización de los recursos ${ }^{49}$. Lo que es también coherente con la consolidada jurisprudencia de la Corte di Cassazione en

46 Sobre el criterio del inversor privado vid. P. MAnZINI, «Note sulle "relazioni pericolose” tra Stato e imprese nel quadro del diritto comunitario», Dir. Un. Eur., núm. 3 (2002), par. 1.

47 Sentencia del Tribunal de Justicia de 24 de julio de 2003, asunto C-280/00, Altmark, párr. 89.

${ }^{48}$ Vid. C. Fontana, Gli aiuti di stato di natura fiscale, Torino, Giappichelli, 2012, p. 230.

49 En línea con este idea vid. C. PetTinari, «Gli "incerti confini” della giurisdizione contabile in tema di responsabilità: note a margine della giurisprudenza più recente in tema di società cc.dd. "in mano pubblica"», Dir. Proc. Amm., núm. 4 (2013), par. 7, y también G. D'AuriA, «Responsabilità dell'amministrazione e responsabilità del funzionario», Foro amm. CdS, núm. 12 (2008), p. 2.1. 
relación con las condiciones para la aplicación de la responsabilidad contable a los administradores de empresas públicas ${ }^{50}$, tal y como la jurisprudencia contable ha afirmado recientemente ${ }^{51}$.

Se puede, por ejemplo, pensar en una compensación por obligaciones de servicio público en el campo del transporte público local ${ }^{52}$. En este caso, la obligación de servicio público podría ser el servicio universal, de acuerdo con un programa de tarifas no necesaria y perfectamente proporcionales a la duración del viaje y según la lógica de la movilidad intermodal. Para hacer frente a estos deberes, en el panorama italiano, frecuentemente las Administraciones locales efectúan compensaciones económicas a las empresas ${ }^{53}$. En este contexto, se podría argumentar que si la sociedad utiliza estos recursos no sólo para garantizar estas obligaciones de servicio público, sino también para diferentes propósitos, los administradores podrían ser responsables en relación con el enjuicimianto realizado por el Tribunal de Cuentas.

En tal caso, mediante la aplicación del método propuesto aquí se podría configurar la responsabilidad contable de los administradores de la empresa, independientemente de si es o no es pública y, por lo tanto, a fortiori, independientemente de su naturaleza in house o no.

Por lo tanto, podemos sugerir que, para los casos analizados en este párrafo y para comprobar la existencia de la jurisdicción contable, se podría considerar si hay una conexión funcional de los recursos de una

50 Vid. Sentencias de Cassazione de 9 de enero de 2013, núm. 295; de 4 de noviembre de 2009, núm. 23332; de 23 de septiembre de 2009, núm. 20434, y de 20 de octubre de 2006, núm. 22513. En la literatura doctrinal vid. S. VALAGUZZA, «Le società a partecipazione pubblica al cospetto della giurisdizione contabile», Riv. Corte Conti (2014), par. 2, e íD., «Le società a partecipazione pubblica e la vana ricerca...», op. cit., par. 3 .

51 Vid. la Sentencia de la Corte dei Conti, Terza Sezione Centrale di Appello, de 25 de julio de 2014, núm. 433, que condenó a los directores de una empresa pública que habían violado las cargas impuestas por la Administración. Vid. también la Corte dei Conti, Campania, Sentencia de 27 de noviembre de 2014, núm. 1613.

52 De hecho, este sector se presenta gráficamente como ejemplo, puesto que, como confirma el estudio realizado por el Banco de Italia en C. Bentivogli, R. Cullino y D. M. DeL Colle, «Regolamentazione ed efficienza del trasporto pubblico locale: i divari regionali», Questioni di Economia e Finanza (Occasional papers), núm. 20 (2008), p. 29, para el transporte público local, en todo el territorio italiano, las tarifas siguen siendo significativamente inferiores a los costes, por lo que juegan un papel decisivo de cara a la compensación regional.

53 Un ejemplo es la región de Lombardía, donde el art. 43, párr. 1, de la Ley Regional de 4 de abril de 2012, núm. 6, establece que el sistema de tarifas regional debe garantizar la imparcialidad del nivel de las tarifas en comparación con la cantidad y calidad del servicio de transporte público, y debe disciplinar la integración de los sistemas de tarifas con el fin de estimular la coordinación entre los diferentes modos y operadores de transporte público [párr. c)]. 
empresa con unos intereses públicos predeterminados por la Administración que otorgó los propios recursos.

Así se podrían superar las contradicciones que surgen de la jurisprudencia de la Cassazione en relación con las empresas in house, al mismo tiempo que se afirmaría la jurisdicción del Tribunal de Cuentas con respecto a cualquier tipo de empresa, ya sea pública o privada.

Por otra parte, esta solución puede también garantizar que las compensaciones pagadas por la Administración sean utilizadas efectivamente para los fines propuestos por la Administración misma, identificando claramente la responsabilidad de los administradores de la empresa por cualquier desviación.

7. De las hipótesis analizadas hasta aquí, han quedado excluidas aquellas en las cuales los recursos otorgados por la Administración no están vinculados a obligaciones de servicios públicos, ni son calificables como ayudas compatibles.

Dichos recursos pueden ser distintos en dos sentidos: medidas que constituyen ayudas incompatibles con el mercado interno y medidas que no caben en la definición del art. 107, párrafo 1, TFUE. Considerando que los primeros, por lo menos en línea teórica, no deberían existir o que, cuando sean otorgados, están ligados a la obligación de restitución, parece más interesante centrarse en los segundos. Éstos, no obstante proceder de una autoridad pública y estar orientados a la financiación de una empresa privada, pueden no ser incluidos en la definición del art. 107, párrafo 1, TFUE cuando, según el criterio del inversor privado, respondan a lógicas privadas, no obstante sean ordenadas por la autoridad pública.

En otras palabras, respecto al marco hasta aquí traído - teniendo siempre claro que el razonamiento desarrollado se refiere únicamente a las sociedades públicas del tipo in house que lleven a cabo actividades de tipo económico - , resta sólo por evaluar cómo puede definirse el régimen de responsabilidad contable respecto a todos aquellos recursos públicos dispuestos por la Administración a través de herramientas de tipo privado, utilizadas con fines de corte empresarial en régimen de competencia.

En este caso, faltando una conexión clara con el interés público, no se podría concretar la jurisdicción contable hacia los administradores de la sociedad, según los criterios analizados hasta aquí. No obstante, tampoco dichos casos se quedan sin cobertura contable. En estos supuestos, se pone en marcha una situación parecida a la del «primer encargo», donde se ha visto que compete a la Administración que adjudica el deber de evaluar la oportunidad del modelo de gestión elegido. Entonces, tam- 
bién en los casos que estamos analizando, donde la Administración que adjudica actúa como «inversor privado», ésta tendrá que evaluar cuidadosamente si la inversión es conveniente y oportuna. Y si no es así como se actúa, se podrá pedir responsabilidad a los funcionarios que hayan tomado la decisión.

Más allá de esta hipótesis, pueden entrar en juego aquellas circunstancias residuales en las cuales, no obstante que la Administración haya demostrado de modo congruente y correcto que el régimen de autoproducción es sostenible, los citados administradores de la sociedad no sean de todas formas capaces de llevar una gestión eficiente, generando así pérdidas monetarias.

Hay que aclarar que dichas hipótesis parecen bastante teóricas, una vez que se han descartado todos los casos mostrados hasta ahora. Una sociedad in house opera normalmente en régimen de monopolio, con tarifas predeterminadas y en un contexto en el cual son sustraídas a los administradores de la sociedad todas las decisiones más importantes. Así que parece difícil que en los actos de gestión que quedan a cargo de los órganos de gobierno de la citada empresa se puedan determinar pérdidas en relación con una gestión perfectamente eficiente según el marco dictado por la Administración.

De todos modos, se ha visto que hay múltiples vías para dirigir la jurisdicción contable hacia los efectivos responsables del perjuicio en todas aquellas hipótesis descritas hasta ahora. Así que, en relación con una hipótesis completamente residual como esta última, no parece para nada oportuno seguir el camino indicado por la Cassazione en tema de responsabilidad contable y sociedades in house. Esto no solamente para los aspectos críticos que la doctrina nacional ${ }^{54}$ - e incluso la misma Corte dei Conti- ${ }^{55}$ ha resaltado, sino también por razones de «oportunidad» europea que, a estas alturas, resulta útil exponer.

8. Finalmente, merece la pena resaltar que la solución recogida por la Cassazione resulta poco oportuna. La jurisprudencia de la Corte, según la cual los órganos de gobierno de una sociedad in house están incluidos en

${ }^{54} \mathrm{Vid}$. G. BotTino, «Le amministrazioni pubbliche e la costituzione, o la partecipazione, di società a capitale pubblico: la legittimità costituzionale dei limiti previsti nell'odierna legislazione statale», in Giur. cost., núm. 3 (2009), par. 1. En dicha perspectiva se puede además recordar C. IBBA, «Responsabilità degli amministratori...», op. cit., par. 1.

${ }_{55}$ Sobre el cual sirve una vez más recordar la critica directa expresada por la Corte dei Conti, Sentencia de 20 de febrero de 2015, núm. 178, hacia la posición asumida por la Cassazione. 
el ámbito de la jurisdicción contable, puede constituir un límite potencial al desarrollo de los servicios económicos de interés general.

Merece la pena recordar que la intervención de las autoridades públicas - en cuanto que sujetos con poderes autoritativos y, por ende, no en calidad de operadores económicos - tendría que estar limitada a la definición de las medidas de compensación por obligaciones derivadas del servicio público y a las medidas de ayuda compatibles con el mercado interior. Fuera de estos casos, los servicios públicos de importancia económica deberían estar regulados íntegramente por las ordinarias reglas del mercado. Y donde, por razones de oportunidad, conveniencia o simple tradición, la Administración prefiere autoproducir o gestionar por sí misma el servicio, existiendo las condiciones materiales para ello, nada impide desde una óptica europea que el operador económico que se encargue de proporcionar las prestaciones esté radicado en manos públicas, aunque sólo parcialmente.

Pero se ha visto que, también en dicho caso, permanece subsistente el principio de base del mercado interno, según el cual el desarrollo de actividades económicas por parte de la Administración no debe ser un obstáculo al desarrollo normal del juego competitivo particular, pudiéndose excepcionar este último sólo en una medida reducida cuando sea necesario para la consecución de intereses generales.

En un contexto de este tipo, parece entonces más coherente con el marco europeo abandonar las soluciones que no distingan, en cuanto al régimen aplicable, entre los momentos de intervención en el mercado de carácter empresarial y aquellos que, al revés, son de matriz típicamente pública. Lo cual estaría además en línea con aquella otra doctrina que, desde hace tiempo, ha propuesto una distinción parecida entre actos anticipatorios a las actividades de la sociedad $-\mathrm{y}$ que, por esto, son expresión de elecciones de carácter público sujetas al escrutinio de la Corte dei Contiy aquellos que, por el contrario, son pura expresión de los poderes del socio según las dinámicas normales previstas en el Código Civil ${ }^{56}$.

En otras palabras, en relación con las sociedades in house que desarrollan actividades de tipo económico, se deberían permitir soluciones que lleven a la afirmación de la jurisdicción contable en cualquier caso, independientemente de la existencia o no de una conexión funcional entre las sumas empleadas por la sociedad y el propósito público.

${ }^{56}$ En dicho sentido vid. A. Maltoni, «Gli atti “prodromici” delle P.A. che incidono sulla struttura e sul funzionamento delle società partecipate», op. cit., par. 6. 
$\mathrm{Al}$ revés, llevar sic et simpliciter todos los recursos de un sujeto privado que opera como ordinaria empresa en el mercado interno a la noción de patrimonio público, con el fin de aplicar a ésta disposiciones de carácter especial y público, corre el riesgo de disminuir la capacidad productiva de los operadores económicos públicos ${ }^{57}$, «aliviando», por otro lado, la presión sobre la elección administrativa del modelo de gestión.

Lo cual es tanto más grave ya que esto puede no conllevar algún beneficio concreto o una mayor tutela de la empresa pública. En perspectiva puramente financiera, se ha visto que en caso de elecciones económicamente inoportunas por parte de la Administración hay siempre, sin embargo, espacio para la acción contable hacia los funcionarios públicos Así como, en el caso de distracción de sumas de dinero proporcionadas para la persecución de fines de interés general, podría de todas formas ser ejercitada la acción contable contra los administradores de la sociedad, in house o de otro tipo.

No se podría argumentar que, acogiendo una perspectiva de este tipo, la posición del administrador de la sociedad quedaría desvinculada en todos los demás casos de mala gestión. En efecto, no se puede subestimar que este último supuesto queda, en todo caso, sujeto a la acción de responsabilidad ex art. 2.393 del Código Civil italiano ${ }^{58}$, cuyas consecuencias no son menos gravosas de aquellas derivadas de la acción contable ${ }^{59}$. También porque, para la protección de los intereses de la Administración en su calidad de socio privado y en caso de inactividad, está además prevista la acción sustitutiva del procurador general en la Corte dei Conti ${ }^{60}$. En tal caso, se podrá entonces como máximo evaluar la oportunidad de ejercer la acción contable contra los funcionarios de la Administración que controla, donde su inactividad haya llevado a una eficacia reducida de la acción de responsabilidad social ex art. 2.393 del Código Civil ${ }^{61}$.

57 Sobre este punto M. AnTONIOLI, Società a partecipazione pubblica, op. cit., pp. 148-149.

${ }^{58} \mathrm{La}$ responsabilidad de los directores ex arts. 2.392 y ss. del Código Civil, de hecho, de acuerdo con una orientación consolidada, debe evaluarse teniendo en cuenta la diligencia mostrada previamente para apreciar el margen de riesgo relacionado con la transacción a realizar (ex multis, Sentencia de Cassazione de 2 de febrero 2015, núm. 1783).

59 Vid. C. IвbA, «Responsabilità degli amministratori...», op. cit., par. 5, según el cual negar la jurisdicción contable no es igual a proporcionar una salida fácil para cualquier responsabilidad.

${ }^{60}$ Ex multis, Sentencia de Corte di Cassazione de 22 de julio de 2014, núm. 16622, en la cual se afirma claramente que existe la legitimidad obligatoria del procurador contable para actuar en interés del socio público no solamente con el fin de suplir a la eventual inercia de éste, sino también con el fin de realizar, por extensión, los objetivos públicos prefijados.

${ }^{61}$ En este sentido vid. C. IвBA, «Responsabilità degli amministratori...», op. cit., par. 5. 
Gherardo Carullo Responsabilidad contable en Italia de los funcionarios públicos...

En consecuencia, si, por un lado, el control contable sobre todas las empresas in house sin distinción alguna puede hacer surgir dudas, por otro, en absoluto parece necesario tal control de cara a proteger el patrimonio público. De hecho, no semeja que el legislador nacional haya entendido necesario afirmarlo. En coherencia con esta perspectiva, se puede entonces concluir que el problema de la responsabilidad debe ser resuelto mediante una más correcta asignación de las responsabilidades, lo cual, debe ser recordado, no significa negar la cobertura de la tutela contable, sino sólo reservar dicha acción contra los sujetos efectivamente responsables según las diferentes dinámicas que han conducido a las pérdidas. 